PALABRAS CLAVE

Finanzas internacionales

Liberalización de mercados financieros

Movimientos de capital

Desarrollo económico

Financiación del desarrollo

Asistencia al desarrollo

Instrumentos financieros

Deuda externa

Jorge García-Arias

Profesor Titular de Economía

Departamento de Economía

Universidad de León,

España

• jrgara@unileon.es

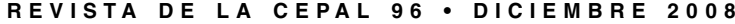

\section{Finanzas internacionales y desarrollo: ¿oportunidad o amenaza?}

\author{
Jorge Garcia-Arias
}

$\mathrm{E}$

volumen de activos que se intercambian en los mercados financieros internacionales ha alcanzado dimensiones gigantescas. Cabe preguntarse entonces si las finanzas internacionales podrían desempeñar un papel decisivo a la hora de proporcionar recursos suficientes y estables para la financiación del desarrollo. En este artículo se analiza la función que las finanzas internacionales podrían tener y la que realmente han tenido en esta materia, centrándose específicamente en el estudio de las corrientes de capital privado, la asistencia oficial al desarrollo y el endeudamiento externo. Se concluye que se precisan reformas estructurales de gran calado en el funcionamiento del sistema financiero internacional y en los instrumentos y mecanismos de financiación del desarrollo, si queremos ponerlos al servicio de objetivos de desarrollo de largo plazo. 


\section{I}

\section{Introducción}

Incluso los análisis menos sofisticados de las estadísticas financieras internacionales ponen de manifiesto la existencia de una disparidad enorme entre la cantidad de activos que circulan por los mercados financieros internacionales y el volumen de esos activos que se destinan a financiar actividades de desarrollo. Por ejemplo, los últimos datos oficiales muestran que diariamente se transan en el mercado de divisas activos por valor de 3.200 miles de millones de dólares - lo que nos ofrece un rango de entre 832.000 y 1.000 .000 de miles de millones de dólares transados a lo largo del año 2007, solo en este mercado (BPI, 2007). Por su parte, el conjunto de los principales donantes de ayuda oficial al desarrollo han destinado a este objeto poco más de 100.000 millones de dólares en el 2007 (OCDE, 2008), mientras que los estudios más rigurosos sobre el tema estiman que serían precisos, anualmente, al menos 50.000 millones de dólares adicionales para alcanzar los principales objetivos de desarrollo a largo plazo (Atkinson, 2005).

Esta dimensión tan espectacular alcanzada por los mercados financieros internacionales es fruto de un largo proceso de liberalización financiera internacional que intensifica las interconexiones de los sistemas bancarios, monetarios y financieros nacionales, y que conduce a la aparición de facto de un espacio financiero mundial al que quedan subordinados. Dicho proceso, a su vez, es consecuencia de una radical ruptura del régimen de regulación de las operaciones financieras y de control de los movimientos de capital, que se inició a finales de los años 1950 con la apertura del Euromercado, recibió un impulso definitivo en los años 1970 y se profundizó en las dos décadas siguientes.

Este fenómeno de globalización financiera es la resultante de un proceso complejo que puede caracterizarse por una serie de elementos, entre los que se incluirían el incremento de la capacidad técnica para el desarrollo

$\square$ Una versión preliminar de este trabajo fue presentada en la maestría de Cooperación Internacional al Desarrollo de la Universidad de Valladolid, España. El autor agradece los comentarios y sugerencias de los evaluadores anónimos de la Revista de la CEPAL, que han contribuido a mejorar sustancialmente el trabajo inicial. Cualquier error que persista es responsabilidad exclusiva del autor. de relaciones financieras avanzadas, la integración de los mercados y agentes nacionales en un mercado más global, una difuminación de las distinciones clásicas entre las instituciones financieras de diversa índole y las actividades y los mercados en los que operan, y el surgimiento de conglomerados bancarios y financieros de dimensión planetaria. ${ }^{1}$

Por otra parte, la mundialización financiera ha consolidado dos tipos de asimetrías de extraordinaria relevancia. De un lado, un escenario con una moneda de referencia claramente hegemónica —el dólar-que vertebra todas las relaciones financieras y comerciales; ${ }^{2}$ de otro, un mercado financiero mundial aparentemente democratizado y con infinidad de pequeños agentes que interaccionan libremente en él, aunque un análisis más detallado muestra un mercado claramente oligopólico, donde un grupo muy reducido de agentes controla la parte principal de los recursos que por él se canalizan y en el que se detectan evidentes comportamientos de rebaño (herd behavior) entre ellos (García-Arias, 2006).

Este proceso de internacionalización y liberalización financieras que, desde un punto de vista teórico, se asentaba en la primera parte del teorema fundamental de la economía del bienestar (TFEB) y en la hipótesis de los mercados eficientes (HME), ${ }^{3}$ suponía una situación en la que todos los actores internacionales ganarían. En general, el capital fluiría desde los países fuertemente desarrollados (excedentarios en capital y con rendimientos

\footnotetext{
${ }^{1}$ Por ejemplo, véase un análisis detallado en Palazuelos (1998).

${ }^{2}$ El rol hegemónico de los Estados Unidos en este contexto de globalización financiera no se manifiesta exclusivamente en el papel central que desempeña su moneda. También se traduce, por ejemplo, en la posibilidad de llevar adelante políticas económicas insostenibles para el resto de las economías, como el mantenimiento de déficit gemelos (el fiscal y el externo corriente) o la capacidad de atraer recursos externos (en parte para financiar dichos déficit gemelos), afectando así la disponibilidad de recursos para otras economías y, por consiguiente, la financiación del desarrollo.

${ }^{3}$ En general, el teorema fundamental de la economía de bienestar se ocupa de la eficiencia en la economía real y la hipótesis de los mercados eficientes enlaza los mercados financieros con los fundamentos macroeconómicos. Combinados, reflejan una situación en la que la eficiencia económica depende de mercados liberalizados (de bienes y servicios, de factores, financieros) y de un sector público minimizado. La liberalización financiera (entre otras) había de ser necesariamente beneficiosa en la medida en que significaba eliminar las distorsiones al libre juego de los mercados, las cuales son, según se afirma, de por sí ineficientes. Véase un análisis teórico al respecto en García-Arias (2002b).
} 
más ajustados) hacia los países emergentes (deficitarios en capital y con retribuciones más altas a dicho factor); esto aceleraría el crecimiento en los países receptores, y tanto donantes como receptores se beneficiarían, dado que las oportunidades de diversificación financiera de ambos crecerían. A este marco general de beneficios potenciales se añadían otros más específicos, como el incremento de la competitividad y eficiencia del sistema, la diversificación internacional de las carteras de inversión, el aumento de las rentabilidades esperadas, la reducción del riesgo y muchos más.

Esta visión idílica, mitológica, del desenvolvimiento de los mercados financieros liberalizados ha sido, cuando menos, puesta en cuarentena tras la proliferación de trabajos que la cuestionan y detectan empíricamente problemas que introducen serios motivos de preocupación. Entre esos problemas destacan el incremento dispar de oportunidades para prestamistas y para prestatarios, el desplazamiento de recursos netos hacia los países más desarrollados, la enorme volatilidad de las corrientes de capital encauzadas hacia los países con menores tasas de desarrollo, la mayor fragilidad del sistema financiero internacional por la profundización de los procesos de crisis cambiarias, bancarias y financieras y el aumento del sobreendeudamiento externo. ${ }^{4}$
A estos problemas habría que añadir los vinculados tanto al origen (actividades ilícitas, blanqueo de capitales) como al destino (financiación de actividades ilegales, paraísos fiscales) de ese gigantesco volumen de capital.

En suma, las finanzas internacionales sin duda podrían hacer una enorme contribución al crecimiento y desarrollo de todas las economías del mundo y al bienestar de la humanidad. No obstante, presentan dificultades que derivan del origen del capital, del tipo de capital, de la forma en que se mueve y de su destino.

De ahí que los muchos retos generados por el proceso de internacionalización y liberalización financiera han propiciado un gran debate en torno a la necesidad de repensar ese proceso y, sobre todo, de modificar la arquitectura financiera internacional. ${ }^{5}$

Sin embargo, desde el punto de vista del desarrollo el principal problema es que dicho proceso no ha contribuido a encauzar corrientes de capital suficientes hacia las economías en desarrollo (y menos aún hacia las de menor desarrollo relativo). Conviene, pues, analizar la relación que se establece, no siempre idílica, entre estos dos fenómenos: las finanzas internacionales y el desarrollo.

\section{II}

\section{Las finanzas internacionales y el desarrollo}

\section{La situación en el cambio de siglo}

Hasta principios del siglo XXI, las corrientes de capital internacionales dirigidas a los países en desarrollo tenían varias características distintivas (Ocampo, 1999a). En primer lugar, las corrientes de capital institucional y las de capital privado habían mostrado tendencias divergentes: mientras las primeras tendían a disminuir, las segundas experimentaban un incremento a medio plazo.

En segundo lugar, los distintos tipos de corrientes de capital privado habían exhibido diferencias notorias en materia de estabilidad: mientras que la inversión extranjera directa (IED) se había mantenido relativamente inalterada durante las crisis, las corrientes financieras

\footnotetext{
${ }^{4}$ Efectuar un análisis detallado de tales cuestiones escapa a los límites del presente ensayo. Véase en Agüera Sirgo y García-Arias (2000) un examen más profundo de las promesas y realidades de este proceso de liberalización e internacionalización financiera.
}

privadas habían mostrado una marcada volatilidad y efectos de contagio. Por su parte, en contraste con el dinamismo mostrado por los flujos de capital privado,

\footnotetext{
${ }^{5} \mathrm{Si}$ bien la idea de reformar la arquitectura financiera internacional es entendida de manera diferente por distintos autores, bajo este epígrafe solemos incluir (la lista no es necesariamente exhaustiva) aspectos relacionados con: i) la mejora de la transparencia y los estándares contables, ii) el incremento de la autorregulación y/o de la supervisión externa, iii) la modificación de los mecanismos de gestión de las cuentas de capital, iv) las modificaciones en la elección de los regímenes de tipos de cambio, v) el diseño de las políticas económicas nacionales y de las que plantean los organismos económicos internacionales, vi) la provisión de liquidez internacional y vii) los mecanismos de prestamista de última instancia y quiebras y suspensiones de pagos internacionales. El tema ha sido intensamente trabajado por la literatura económica y ha experimentado un crecimiento exponencial en la última década. Evidentemente, este trabajo no pretende exponer las diferentes aportaciones y enfoques de la cuestión, pero el lector interesado puede consultar, entre otros muchos, los trabajos de Caballero (2003), Eatwell (2002), Eichengreen (1999), Griffith-Jones, Gottschalk y Cailloux (2003), Kenen (2001) y Ocampo (1999b).
} 
la financiación oficial para el desarrollo (y sobre todo su principal componente, los fondos de asistencia bilateral) había tenido una evolución poco satisfactoria (aid fatigue), disminuyendo en términos reales a lo largo de la década.

En tercer lugar, las corrientes de capital privado se habían concentrado en los países de ingreso medio, tendencia que solo había sido compensada parcialmente por el efecto redistributivo de las corrientes financieras públicas a nivel mundial.

Por último, la volatilidad de las corrientes financieras privadas, por una parte, y su fuerte concentración en los países de ingreso medio, por otra, habían terminado generando necesidades de financiación excepcional de magnitudes sin precedentes. Esa financiación excepcional se había dirigido a unas pocas economías emergentes. Como consecuencia, el financiamiento proveniente del Fondo Monetario Internacional (FMI), incluido el del servicio financiero reforzado de ajuste estructural, había presentado una marcada trayectoria anticíclica en relación con las corrientes de capital privado y se había concentrado en un escaso número de países, los que debieron cumplir con exigencias de política económica de sobra conocidas (ajuste estructural).

Así las cosas, aunque la volatilidad y el contagio que mostraban las corrientes de capital privado eran indudablemente problemáticos, también lo eran la marginación de los países más pobres de las corrientes de capital privado y la reducción de la asistencia bilateral de la que dependían en gran medida. La reforma de la estructura financiera internacional, por lo tanto, debía ofrecer soluciones a todos estos problemas. Además, el excesivo endeudamiento de muchos países en desarrollo, sobre todo de los más pobres, seguía limitando notablemente sus posibilidades de desarrollo.

En este contexto, los Jefes de Estado y de Gobierno, reunidos en la Conferencia Internacional sobre la Financiación para el Desarrollo que se realizó en Monterrey, México, bajo el auspicio de las Naciones Unidas, adoptaron una resolución para hacer frente a los problemas de esta índole: el Consenso de Monterrey (Naciones Unidas, 2002).

\section{El Consenso de Monterrey}

El Consenso de Monterrey está construido sobre la idea de que la cooperación internacional al desarrollo debe ser vista como una tarea en la que deben participar tanto los países desarrollados como los países subdesarrollados y/o en vías de desarrollo (PSVD).

Más concretamente, en esta alianza cada PSVD acepta ser el principal responsable de su propio desarrollo, por lo cual deberá i) mejorar su gobernanza interna; ii) combatir la corrupción; iii) implementar las políticas y efectuar las inversiones que conducen al crecimiento y al empleo, y iv) maximizar los recursos nacionales disponibles para financiar estrategias de desarrollo adicionales. Por su parte, los países desarrollados acuerdan que aquellos PSVD que adopten estrategias de desarrollo transparentes, creíbles y bien diseñadas deben recibir el apoyo pleno que necesitan, en forma de i) mayor asistencia para el desarrollo; ii) un sistema de comercio internacional más orientado al desarrollo; iii) medidas de alivio o condonación del endeudamiento, y iv) un aumento de la financiación privada para el desarrollo. Y, por último, las instituciones internacionales garantes del Consenso aceptan i) acrecentar la coherencia de sus actuaciones; ii) coordinarse y cooperar en la programación de sus actividades y en la implementación de políticas de desarrollo internacionales, y iii) modificar la estructura y el funcionamiento del sistema financiero internacional para ayudar a la consecución de estos objetivos.

Para ello, el Consenso de Monterrey distinguió seis aspectos principales relacionados con el desarrollo: i) la movilización de recursos financieros nacionales de los propios PSVD; ii) el uso del comercio internacional como instrumento de desarrollo; iii) la afluencia de capital internacional privado hacia los PSVD; iv) la asistencia oficial para el desarrollo; v) el endeudamiento externo, y vi) el sistema financiero internacional y su relación con el financiamiento para el desarrollo.

Aunque los dos primeros son sin duda cruciales en un enfoque holístico de la financiación para el desarrollo, escapan del ámbito estricto de las finanzas internacionales en las que se centra este ensayo. Por otra parte, resulta evidente que es preciso modificar, como ya se ha señalado, la arquitectura general del sistema financiero internacional con el propósito, entre otros, de convertir el proceso de liberalización financiera en un elemento dinamizador del desarrollo. En todo caso, el resto del trabajo se centrará en las cuestiones relacionadas con las corrientes de capital privado, con la asistencia oficial para el desarrollo (AOD) y con el endeudamiento externo. 


\section{III}

\section{Las corrientes internacionales de capital privado}

En teoría, las corrientes de capital privado pueden desempeñar un papel muy importante en el desarrollo de los países receptores. Sin embargo, como lo hemos señalado, la evidencia empírica indica que en las últimas décadas dichos flujos no solo han sido escasos, volátiles y altamente reversibles — viéndose afectados por comportamientos grupales y de contagio-, sino que además han tendido a circunvalar a los países más empobrecidos.

Aunque la inestabilidad, la volatilidad y el comportamiento de rebaño son elementos inherentes a los mercados financieros (nacionales e internacionales), no todos los tipos de capital exhiben estas características en igual medida. En concreto, la IED es mucho más estable que otras formas de capital (como la inversión de cartera o los créditos bancarios).

Por otro lado, no toda la responsabilidad de esta situación recae en los mercados internacionales. También los propios sistemas financieros de los países receptores exhiben diferencias con los de países más desarrollados que incrementan su fragilidad. Estas diferencias son las siguientes:

- la incapacidad de muchos PSVD de emitir obligaciones denominadas en su propia moneda, especialmente a largo plazo (el "pecado original", según Eichengreen, Hausmann y Panizza, 2003); esto genera un gran conjunto de fragilidades en los sistemas financieros nacionales, al conectarlos básicamente con el dólar.

- las diferencias en el nivel de desarrollo de sus sistemas financieros y de sus mercados de capitales, lo que lleva a una escasa disponibilidad de instrumentos financieros de largo plazo en estos mercados.

- el reducido tamaño de los mercados financieros internos de estos países frente a los gigantescos mercados financieros internacionales.

La historia reciente de los movimientos internacionales de capital muestra tres oleadas de capital privado hacia los PSVD. Las dos primeras tuvieron lugar en la década de 1970 y en la de 1990.

- En la de los años 1970, el rápido crecimiento de los créditos bancarios otorgados a los países en desarrollo — por el reciclaje de los ingentes superávit externos de los países productores de petróleo y la desregulación de mercados financieros nacionales e internacionales - fue interrumpido por la crisis de la deuda en América Latina (y otras regiones económicas).

- La de los años 1990, dominada por las corrientes de IED e inversión de cartera, especialmente hacia los países del sudeste asiático, fue cortada de raíz por las crisis cambiarias y financieras que sufrieron estos países a finales de la década ${ }^{6}$ y que se extendieron a Rusia y América Latina.

La tercera oleada se inició el 2003 y continúa hasta hoy, como consecuencia de la mejora de las condiciones económicas en los PSVD, del panorama mundial de crecimiento económico y de la persistente política de intereses bajos en los países desarrollados.

Este tercer ciclo de recuperación de las corrientes de capital hacia los PSVD difiere no obstante de los dos precedentes (Ocampo, Kregel y Griffith-Jones, 2007). En concreto, en el período 1997-2005 hubo una transferencia neta de recursos desde los PSVD hacia los países desarrollados, debida fundamentalmente a la enorme cantidad de reservas que están acumulando los países en desarrollo (especialmente los del sudeste asiático) como seguro frente a crisis financieras futuras $-\mathrm{y}$ a la fecha de revisión de este trabajo ya concretadas-. Además, aumentó significativamente la concentración de las corrientes de capital hacia los PSVD en el este y el sudeste asiáticos, y muy particularmente en China, a expensas de América Latina.

En este escenario generalizado de recuperación de las corrientes privadas de capital hacia los PSVD, la preocupación fundamental de estos últimos no es solo saber si ellas serán suficientes para financiar su desarrollo, sino también saber si mostrarán cierta estabilidad o si —como ha venido siendo habitual— serán marcadamente volátiles y reversibles.

En tal sentido, conviene tener claro, como indicamos más atrás, que no todas las corrientes de capital privado - es decir, la IED, la inversión de cartera y los créditos bancarios - exhiben la misma volatilidad.

La IED tiene tres componentes principales: la inversión en bienes de capital, las utilidades locales reinvertidas localmente y los préstamos intrafirma.

\footnotetext{
${ }^{6}$ Véase en García-Arias (2002a) un análisis detallado de las crisis asiáticas.
} 
En el último ciclo, la IED — sobre todo la dedicada a bienes de capital - se convirtió en la fuente principal de financiamiento externo y ha demostrado ser, a lo largo de la historia, mucho más estable que el resto de las corrientes internacionales. Por lo demás, ofrece ventajas adicionales: entre otras, eleva la productividad de los países receptores por la transferencia de tecnología y conocimiento técnico (know-how) y facilita el acceso a los mercados internacionales de bienes y financiamiento.

No obstante, la IED también presenta inconvenientes: por ejemplo, sus vínculos con la estructura económica local suelen ser muy limitados, exacerba los déficit comerciales y restringe la competencia y la inversión de riesgo en los países de destino.

Aunque el debate es intenso en torno al monto real de los beneficios de la IED y al desfase temporal con que los reciben los países de destino, la literatura económica suele convenir en que el saldo neto es positivo, pero con enormes diferencias entre los distintos países y dentro de cada uno de ellos.

En este último ciclo los beneficios claramente han crecido, lo que resulta esperanzador, sobre todo porque la inversión en bienes de capital viene representando unas dos terceras partes de la IED total (Banco Mundial, 2004). Además, se detectan algunos cambios en la composición y destino de la inversión. Lo más relevante es su rápido crecimiento en el sector servicios, principalmente por la expansión de las empresas transnacionales en ese segmento de los PSVD, debida en muchos casos a procesos de privatización. Aunque en general el comportamiento anticompetitivo característico de las empresas transnacionales tiene consecuencias adversas cuando la normativa para la defensa de la competencia local es laxa, la IED en el sector terciario ha tenido efectos diferentes en las distintas áreas económicas de destino. Por ejemplo, el salto hacia el sector servicios de la IED en América Latina parece haber tenido un efecto de expulsión sobre las compañías locales (Agosin y Mayer, 2000). Algo similar ha sucedido en el sector bancario latinoamericano, aunque esta orientación de la IED hacia los sectores financieros parece haber generado efectos más positivos en el sudeste asiático (Banco Asiático de Desarrollo, 2004) o en los países del este europeo (Weller, 2001). Otro aspecto relevante de la IED es el crecimiento de las corrientes Sur-Sur, que benefician en especial a los PSVD de menores ingresos y nivel de desarrollo. No obstante, el conjunto de la IED presenta un problema: el 75\% de ella se concentra en solamente 10 países.

$\mathrm{Al}$ tenor de lo expuesto, los PSVD podrían aplicar un conjunto de medidas para lograr que la IED contribuya más al desarrollo, entre ellas las siguientes: formular políticas que potencien los enlaces entre las empresas extranjeras y las locales; favorecer las exportaciones con alto valor agregado y la transferencia de conocimientos, destrezas y tecnología; incentivar a las empresas extranjeras para que inviertan en la formación del factor trabajo, y crear un clima económico interno favorable mediante inversiones en infraestructura y capacitación, códigos de conducta transparentes y estabilidad normativa.

Por otro lado, la inversión de cartera tiende a ser procíclica y fuertemente reversible y volátil. Durante años (en las dos oleadas anteriores) fue la fuente principal de la afluencia de capital internacional privado hacia los PSVD, alcanzando su punto más alto en 1996. A partir de ese momento, como consecuencia de las crisis cambiarias y financieras asiáticas y sus contagios, experimentó una fuerte caída, de la que está recuperándose en los últimos años. Pese a que sus efectos pueden llegar a ser devastadores en el caso de una reversión rápida, continúa siendo la fuente principal de financiación de la deuda en los PSVD, especialmente en América Latina.

En cuanto a los créditos bancarios, cabe señalar que ellos pueden contribuir en cierta medida al desarrollo, especialmente si están ligados a transacciones comerciales internacionales. Son proporcionados por bancos, instituciones financieras y no financieras, organismos oficiales de exportación, bancos de desarrollo regionales, aseguradoras privadas y compañías especializadas.

Su participación creció marcadamente hasta las crisis de 1997; de hecho, tuvo una responsabilidad importante en el fenómeno, básicamente al incentivar un ciclo auge-depresión (García-Arias, 2002a) y al potenciar el comportamiento de rebaño en los agentes (García-Arias, 2006). Su papel, sobre todo en el caso de los créditos comerciales, tiene especial importancia para países de bajos ingresos que difícilmente acceden a otras clases de financiamiento en los mercados internacionales. En este sentido, convendría alentar el papel de las agencias oficiales de exportación y de los bancos de desarrollo regionales, como el Banco Interamericano de Desarrollo (BID) y el Banco Asiático de Desarrollo, para que actúen de manera contracíclica mediante garantías y avales para créditos de esta índole. 


\section{IV}

\section{La asistencia oficial para el desarrollo}

\section{Las fuentes tradicionales de esta asistencia}

La asistencia oficial para el desarrollo (AOD) sigue siendo fundamental para suplementar los recursos de los PSVD, sobre todo en el caso de economías muy empobrecidas que tienen especiales dificultades para atraer capital privado. Sin embargo, tras alcanzar un máximo de $0,5 \%$ del producto interno bruto (PIB) de los países más desarrollados en la década de 1960, dicha asistencia cayó hasta un histórico 0,22\% del PIB en los momentos previos a los acuerdos de la Cumbre del Milenio, de las Naciones Unidas. En este sentido, el Consenso de Monterrey reafirma el objetivo tradicional de que la asistencia alcance al menos el 0,7\% del PIB de los países donantes (del cual al menos un 0,15-0,20\% debería destinarse a los países pobres muy endeudados (los PPME).

En el 2007, la AOD de los principales donantes - los 22 países miembros del Comité de Asistencia para el Desarrollo (CAD) — superó los 103.000 millones de dólares (cifra 8,4\% inferior a la del 2006). Esta asistencia representó un 0,28\% del PIB del conjunto de países del comité (OCDE, 2008).

La caída experimentada por la AOD después del 2005 se debe, paradójicamente, al tipo de partidas de ayuda que causaron el fuerte incremento de ese año. Así, las operaciones de condonación de deuda externa representaron cerca de 23.000 millones de dólares cuando el incremento total ascendía a más de 26.000 millones. Descontando las operaciones de condonación de deuda en el 2005, el incremento de la AOD respecto del año anterior se hubiese limitado a cerca del $9 \%$ en dólares corrientes. Por el carácter excepcional de estos paquetes de asistencia centrados en la condonación de deuda $-\mathrm{y}$, en muy menor medida, en ayuda de emergencia tras el devastador tsunami del 2004 en las costas del este y sudeste de Asia- era difícil que se mantuviera el ritmo de crecimiento.

A la hora de valorar la cuantía de la asistencia oficial para el desarrollo conviene tener presente que, según los datos disponibles, se precisan anualmente unos 50.000 millones de dólares de AOD adicional para alcanzar los objetivos de desarrollo más perentorios (Naciones Unidas, 2001). Por ejemplo, garantizar la escolarización primaria universal demandaría unos 10.000 millones de dólares adicionales por año, reducir la pobreza extrema a la mitad unos 20.000 millones de dólares adicionales por año y disminuir la mortalidad materna e infantil unos 12.000 millones de dólares anuales adicionales (HM Treasury, 2003). Esto nos lleva a establecer que el nivel de AOD ha tendido a ser insuficiente.

Además, pese a que su valor total creció desde fines de los años 1990, la asistencia oficial para el desarrollo presenta algunos problemas importantes:

i) Su composición. Los cambios en la composición de la AOD hacen más difícil que esta asistencia sea eficaz para alcanzar objetivos de desarrollo sólidos. La razón es que los tres componentes que más han crecido en los últimos años son el alivio de la deuda, la ayuda de emergencia y la cooperación técnica. Aunque todos cumplen funciones importantes, la ayuda de emergencia no está diseñada para lograr objetivos de desarrollo de largo plazo y la cooperación técnica, que puede proporcionar beneficios importantes para el desarrollo, solo tiene un impacto financiero real pequeño. En consecuencia, la AOD ha ido decreciendo como fuente de recursos financieros para los países receptores, en lo que se refiere a lograr objetivos de desarrollo. Esta situación es evidente sobre todo en el caso de los países pobres muy endeudados, dado que si se descuenta la ayuda de emergencia y el alivio de la deuda, la asistencia oficial para el desarrollo se ha visto reducida casi en $50 \%$ desde el inicio del programa de los objetivos del Milenio (Ocampo, Kregel y Griffith-Jones, 2007).

ii) Su volatilidad. Para el eficaz cumplimiento de objetivos de desarrollo de largo plazo se precisa cierta estabilidad en las corrientes de inversión y en la afluencia de ayuda a lo largo del tiempo. Sin embargo, las corrientes de AOD han mostrado una clara tendencia cíclica ligada a los ciclos económicos de los países donantes, la cercanía ideológica, política o cultural de los países receptores y las variaciones de las políticas de desarrollo en los países donantes. Esta situación reviste especial gravedad, porque la AOD tiene a su vez un efecto procíclico (Pallage y Robe, 2001; Bulir y Hamann, 2003): cuando la ayuda cae, provoca severos ajustes fiscales en el país receptor (reducción de gastos públicos, incremento de los ingresos públicos), lo 
que refuerza el efecto del descenso de los fondos de asistencia.

iii) Su condicionalidad. No solo los países donantes imponen exigencias específicas a los receptores, sino que estas habitualmente vienen acompañadas del requisito de que estos países sean miembros del Fondo Monetario Internacional (FMI) y cumplan razonablemente con sus programas de ajuste estructural. El incumplimiento de los requisitos del FMI tiene un doble efecto adverso: hace perder la ayuda del FMI y también los fondos de AOD de los países donantes.

iv) Su concentración espacial. La AOD se concentra en unos pocos países receptores, a saber, los que han llevado a cabo reformas estructurales auspiciadas por los organismos financieros internacionales y que son vistos por los donantes como gestores eficientes de la ayuda.

Por otro lado, conviene tener claro que no hay evidencia empírica concluyente de que la AOD sea eficaz para reducir la pobreza y estimular el crecimiento y el desarrollo. Numerosos estudios señalan que esta asistencia funciona bien solo cuando va dirigida a países que aplican "buenas políticas", entendiendo por tales las del Consenso de Washington (Banco Mundial, 1998; Burnside y Dollar, 2000; Collier y Dollar, 2001). Otros trabajos, en cambio, achacan los resultados de esos estudios a problemas en la especificación econométrica de los modelos (Hansen y Tarp, 2000: Beynon, 2003), e incluso encuentran evidencia de que la ayuda favorece el crecimiento, con independencia del "ambiente político" (Morrissey, 2001). Y algunos concluyen que no son las "buenas políticas" sino otras variables —como la vulnerabilidad económica, la existencia de perturbaciones externas (Collier y Dehn, 2001), la presencia de conflictos (Collier y Hoeffler, 2002) e incluso factores geográficos (Dalgaard y Hansen, 2001) - las que influyen significativamente en la eficacia de la ayuda.

No obstante, los temas de la buena gobernanza, los cambios institucionales y la puesta en práctica de políticas ortodoxas siguen dominando el debate.

En todo caso, los países donantes están cada vez más preocupados de las cuestiones relativas a la eficacia de su ayuda. En este sentido, en el 2003 se llevó a cabo en Roma el Foro de Alto Nivel sobre Armonización, y luego en París el Foro de Alto Nivel sobre la Eficacia de la Ayuda, con miras a elaborar un plan de acción tendiente a armonizar (entre ellos y con los países receptores) las políticas de asistencia y las prácticas y procedimientos de los donantes.
Otro elemento destacable de la AOD es lo que se ha llamado la cooperación Sur-Sur, esto es, el hecho de que algunos PSVD donen ayuda para el desarrollo a otros PSVD. Si bien tradicionalmente el donante principal ha sido Arabia Saudita, seguida por los Emiratos Árabes y Kuwait, otras naciones, como China y la República de Corea, se han incorporado y están adquiriendo un peso creciente. Básicamente se trata de cooperación técnica, o de foros de consulta y coordinación, por lo general en áreas económicas o sectoriales específicas (un ejemplo es el Foro de Diálogo IBSA, con participación de India, Brasil y Sudáfrica).

\section{Los instrumentos innovadores del financiamiento para el desarrollo}

En los últimos años, principalmente como consecuencia de la dificultad política para cumplir el objetivo de que la AOD llegue al 0,7\% del PIB de los países donantes, han aparecido varias propuestas para financiar el desarrollo, distintas de las tradicionales. Se trata de propuestas muy diversas que apuntan a aumentar en el corto plazo el volumen de recursos financieros destinados al desarrollo de los países pobres, con el fin de maximizar las probabilidades de cumplimiento de los objetivos de desarrollo del Milenio para el 2015.

La propia Asamblea General de las Naciones Unidas, en su resolución S-24/2 del 1 de julio del 2000, llamó al estudio riguroso de las ventajas, desventajas e implicaciones de un conjunto heterogéneo de "fuentes innovadoras de desarrollo, tanto privadas como públicas". Asimismo, la Comisión Europea ha estimulado el estudio y el debate sobre estas nuevas fuentes de financiación para el desarrollo (Comisión de las Comunidades Europeas, 2005). ${ }^{7}$

En este cajón de sastre de instrumentos innovadores para la financiación del desarrollo caben propuestas muy heterogéneas, pero algunas de las principales son: i) las plataformas de emisión de nuevos instrumentos financieros que permitan adelantar fondos para el desarrollo, como el propuesto servicio de financiación internacional (IFF por su sigla en inglés) ${ }^{8}$ o la emisión de nuevos derechos especiales de giro en el FMI; ii) las donaciones a alianzas público-privadas y a fondos globales; iii) las medidas para lograr que las remesas de los migrantes tengan un

\footnotetext{
${ }^{7}$ Se han dado algunos pasos en esta dirección, puesto que las Naciones Unidas ha financiado y publicado un estudio sobre el tema llevado a cabo por prestigiosos expertos mundiales en cuestiones de financiación para el desarrollo (Atkinson, 2005).

${ }^{8}$ International Finance Facility.
} 
mayor impacto sobre el desarrollo; iv) los impuestos globales (sobre algunas transacciones financieras, el tráfico de armas, las emisiones de gases contaminantes o los billetes aéreos), y v) una lotería mundial.

El servicio de financiación internacional es un mecanismo de financiación del desarrollo propuesto por el Reino Unido (HM Treasury, 2003), que permitiría prefinanciar el desembolso de la ayuda gracias a un plan de endeudamiento garantizado por los Estados participantes con la finalidad de duplicar las actuales corrientes de ayuda y permitir que se alcancen los objetivos del Milenio. Este instrumento aportaría una nueva fuente de financiación estable y previsible y funcionaría de la siguiente manera: primero registraría los compromisos de contribuciones futuras irrevocables, formales y plurianuales de los países donantes, que serían sus accionistas; a continuación, emitiría bonos en los mercados financieros cuyo pago estaría garantizado por los compromisos de los donantes. Estos bonos, por estar plenamente respaldados, tendrían la máxima calificación crediticia, lo que permitiría generar recursos a tasas de interés menores a las que tendrían que pagar los PSVD por endeudarse; por último, los ingresos generados por la emisión de bonos serían distribuidos a los países en desarrollo en forma de donaciones, nunca de préstamos. Además, los fondos estarían "reservados", es decir, destinados a países, programas o proyectos beneficiarios concretos, según la decisión de los países donantes. Estos últimos podrían fijar también condiciones para el desembolso de la ayuda.

Por otro lado, los derechos especiales de giro (DEG) son, como se sabe, activos de reserva internacionales emitidos por el FMI para complementar las reservas oficiales de los países miembros. Se asignan en proporción a las cuotas de cada miembro en el Fondo, sirven también como unidad de cuenta internacional y su valor está basado en una cesta de las principales monedas del mundo. Los DEG representan un activo potencial frente a las monedas de libre uso de los países miembros del FMI. Los tenedores de DEG pueden obtener esas monedas a cambio de sus derechos mediante dos operaciones: primero, se conciertan acuerdos de canje voluntario entre países miembros; segundo, el FMI designa países miembros con una sólida situación externa para que compren DEG a miembros con una situación poco firme. Solo los gobiernos, los bancos centrales, el FMI y otros pocos tenedores oficiales pueden poseer DEG. La asignación de DEG proporciona a cada miembro un activo gratuito por el que devenga y paga intereses netos a la misma tasa. Por lo tanto, si las tenencias de DEG de un miembro superan el nivel asignado, este devenga intereses sobre el excedente; a la inversa, si mantiene menos DEG de los asignados, paga intereses sobre el déficit.

La Junta de Gobernadores del FMI aprobó en septiembre de 1997 una asignación excepcional de DEG mediante la propuesta de una cuarta enmienda del Convenio Constitutivo. Ella duplicaría las asignaciones, que llegarían a una cifra acumulada de 42.900 millones de DEG, con lo cual todos los miembros del FMI, antiguos y nuevos, podrían participar de forma equitativa en el incremento de las reservas de DEG. No obstante, la cuarta enmienda mencionada todavía no ha entrado en vigor, por falta del necesario consenso entre los miembros del FMI. Por lo tanto, ante todo habría que conseguir el apoyo político necesario para su aprobación. Enseguida, los países desarrollados —que reúnen el $60 \%$ de las cuotas- podrían llegar a un acuerdo para poner sus asignaciones a disposición de los países en desarrollo o de fondos multilaterales capaces de conceder préstamos anticíclicos adaptados a los PSVD.

Las remesas de los migrantes, que según datos del Banco Mundial se aproximaron a los 200.000 millones de dólares en el 2006, pueden ser importantes para el desarrollo, básicamente por dos razones: i) suelen ser menos procíclicas que otras corrientes de capital privado, con lo que constituyen una fuente de financiación más estable y previsible; ii) los ingresos derivados de las remesas suelen destinarse a gastos como la alimentación, la vivienda y los servicios básicos, de modo que constituyen una red de seguridad alternativa para los PSVD. Como los costos de intermediación y transferencia de las remesas son considerables, toda reducción significativa de ellos repercutiría directamente en la lucha por el desarrollo. En este sentido, el objetivo concreto más importante es abaratar el costo de envío y fomentar la bancarización y la inversión en capital físico y humano en los países receptores de remesas.

En relación con las alianzas público-privadas y los fondos globales, la idea es fortalecer los incentivos tributarios y económicos a la generosidad privada, para lograr el compromiso de los ahorradores en el circuito de las finanzas solidarias y apoyar de esta forma las iniciativas de carácter económico de los socios y de personas naturales o jurídicas que actualmente están excluidas del sistema bancario. En concreto, se estudia establecer nuevos mecanismos que estimulen a los consumidores, productores, filántropos y banqueros a contribuir a las acciones de solidaridad internacional. Un ejemplo de tales mecanismos sería la utilización de etiquetas que identifiquen a los donantes y de medios de pago que actúen de intermediarios en estas operaciones (por ejemplo, tarjetas de crédito). 
Por otra parte, los activos monetarios y financieros son objeto de intercambio en mercados amplios, profundos y líquidos, muchos de los cuales operan a nivel mundial. Por lo tanto, las transacciones financieras internacionales (de divisas y valores) representan una base tributaria atractiva y muy dinámica. De ahí la idea de proponer un impuesto sobre tales transacciones.

Con tasas impositivas muy bajas $(0,1 \%-0,2 \%$ en las propuestas más ambiciosas y $0,01 \%-0,02 \%$ en las más moderadas $)^{9}$ podrían obtenerse ingresos elevados, siempre que se apliquen de forma relativamente coordinada entre los principales centros financieros. Además, estos impuestos pueden ayudar a corregir externalidades si con ellos se eliminan transacciones consideradas de utilidad nula o negativa desde el punto de vista de la eficiencia del mercado, ya que generan una excesiva volatilidad de los precios. ${ }^{10}$

El efecto que un impuesto tendría sobre las decisiones de inversión sería probablemente muy escaso en comparación con el que tendrían otras medidas o con el impacto de la regulación prudencial sobre las decisiones de cartera de muchas entidades e intermediarios financieros.

Los impuestos sobre las transacciones financieras suelen ser objeto de crítica desde el punto de vista de la eficiencia económica: se alega que elevarían los costos y reducirían el volumen de las transacciones; que modificarían artificialmente el horizonte temporal del inversor a costa del corto plazo; que reducirían la liquidez del mercado y con ello podrían contribuir indirectamente a aumentar la volatilidad, y que por su propia naturaleza darían lugar a fenómenos en cascada. Además, se aduce que no se puede conocer ni prever su impacto real, que podría ser muy superior al gravamen teórico. Que su incidencia sería arbitraria y existiría un riesgo de doble imposición (sobre todo con respecto a las transacciones efectuadas a través de intermediarios o empresas de inversión colectiva). Y que existiría un peligro importante de evasión. No obstante, las últimas aportaciones al debate (Nissanke, 2005) parecen haber dejado claro que existen mecanismos técnicos para establecer dicho gravamen y minimizar las distorsiones que cause. El único obstáculo que persiste es, evidentemente, de naturaleza política (Agüera Sirgo y García-Arias, 2000).

\footnotetext{
${ }^{9}$ Véase en Nissanke (2005) un análisis detallado de las propuestas.

${ }^{10}$ Las operaciones con divisas representarían un caso especial; un posible objetivo de un impuesto sobre las transacciones en divisas sería el de combatir la especulación y contribuir a la estabilización de los tipos de cambio (Agüera Sirgo y García-Arias, 2000).
}

En la literatura económica han surgido diversas propuestas en torno a la idea de gravar diferentes actividades generadoras de externalidades ambientales negativas: por ejemplo, los llamados impuestos pigouvianos o, cuando se relacionan con la protección del medio ambiente, impuestos ambientales. De todas esas propuestas, la que ha recibido mayor atención es un impuesto sobre la emisiones de gases de efecto invernadero (y muy especialmente de $\mathrm{CO}_{2}$ ). Quizá este ámbito de la tributación ambiental, que escapa a los límites del presente ensayo, sea el que más publicaciones ha generado en los últimos años. ${ }^{11}$

En relación con estos instrumentos de financiación innovadores, cabe destacar aquí algunas conclusiones (Atkinson, 2005):

i) los únicos dos impuestos mundiales capaces de generar recursos suficientes para alcanzar el objetivo presupuestario considerado (unos 50.000 millones de dólares adicionales por año) serían un impuesto sobre las transacciones financieras internacionales y un impuesto sobre las emisiones de $\mathrm{CO}_{2}$. Ambos son técnicamente factibles y tendrían un impacto limitado sobre la eficiencia y la producción.

ii) dado que las tasas impositivas propuestas, viables desde el punto de vista técnico y político, se sitúan en el extremo inferior de la banda posible, son pocas las posibilidades de generar dobles dividendos. Seguramente no quedará más remedio que escoger entre instrumentos de financiación para el desarrollo e instrumentos para enfrentar externalidades negativas.

iii) existen alternativas a los impuestos globales: el incremento de recursos necesario se alcanzaría con solo cumplir el requisito de destinar el $0,7 \%$ del PIB de los países desarrollados a la cooperación para el desarrollo, implementando el servicio de financiación internacional.

iv) el impacto económico global de los diferentes instrumentos de política solo puede aproximarse ex ante. Mientras esas medidas no sean puestas en práctica será imposible conocer su impacto real y los beneficios y costos totales asociados a ellas.

De las medidas propuestas, solo se han llevado a la práctica tres iniciativas innovadoras: un impuesto sobre los billetes aéreos, el Servicio Financiero Internacional

\footnotetext{
11 Véase en Sandmo (2005) una excelente evaluación de las posibilidades de generar recursos para el financiamiento del desarrollo mediante los impuestos ambientales, así como un repaso de la literatura sobre el tema.
} 
para la Inmunización (IFFIM, por su sigla en inglés) y los compromisos anticipados de mercado (AMC, por su sigla en inglés), ${ }^{12}$ que aseguran futuros mercados viables para vacunas o medicamentos que se estén investigando (Olivié y Steinberg, 2007).

En el 2004, Francia, junto con Chile y el Reino Unido, propuso la creación de un impuesto nacional (no mundial) sobre los billetes aéreos. En la Conferencia sobre Fuentes Innovadoras de Financiación del Desarrollo (París, febrero del 2006) Brasil, Chipre, Congo, Costa de Marfil, Gabón, Isla Mauricio, Jordania, Luxemburgo, Madagascar, Nicaragua y el Reino Unido apoyaron la propuesta y se comprometieron a crear el impuesto a medio plazo, pero no fijaron una fecha concreta para hacerlo. Actualmente casi una veintena de países ha dado su apoyo a la iniciativa. Los recursos que se obtengan serán gestionados por UNITAID (organismo creado en septiembre de 2006 en el seno de la Organización Mundial de la Salud) con el propósito de mejorar el acceso a tratamientos contra el VIH-SIDA, la malaria y la tuberculosis en los PSVD, a precios más bajos que los de mercado. Aunque la recaudación esperada sea poca (unos 450 millones de dólares anuales), constituye el primer ejemplo de que, existiendo voluntad política, es posible concebir impuestos innovadores y llevarlos a la práctica en un contexto internacional.

El Servicio Financiero Internacional para la Inmunización, mencionado más atrás, tuvo su origen en la ausencia de un acuerdo suficiente para la implementación del propuesto IFF (básicamente en lo relativo a gobernanza, destino de los fondos y niveles de apalancamiento). Siendo este el caso, se optó por establecer una suerte de IFF reducido, destinado a financiar un programa de vacunaciones a gran escala.

En este sentido, todos los nuevos fondos que se generen financiarán programas de salud, en particular vacunaciones. Esto porque existe consenso en torno a la idea de que las vacunaciones están relacionadas con bienes públicos globales de elevada rentabilidad de largo plazo y de que no actuar (no vacunar) socavaría el potencial de crecimiento y desarrollo de los PSVD. El proyecto, que comenzó a operar en noviembre del 2006 y que generará 4.000 millones de dólares por año hasta el 2015, está financiado por Alemania, Austria, Brasil, Francia, España, Italia, el Reino Unido y Suecia, y por la Bill and Melinda Gates Foundation. Los recursos obtenidos mediante donaciones de estos contribuyentes serán gestionados y distribuidos por la Alianza Mundial para las Vacunas y la Inmunización (GAVI, ${ }^{13}$ por su sigla en inglés), en la que participan el Banco Mundial, la Organización Mundial de la Salud (OMs), el UNICEF, la Bill and Melinda Gates Foundation y varios gobiernos de países donantes y receptores. Las donaciones se destinan a la compra de vacunas y a su distribución a 72 países con ingreso anual per capita inferior a 1.000 dólares, lo que permitirá acelerar el cumplimiento de varios objetivos de desarrollo del Milenio en los países de menores ingresos (de manera directa, la reducción de la mortalidad infantil y la mejora de la salud materna; de manera indirecta, la reducción de la pobreza y la mejora de la educación).

Por lo que se refiere a los AMC, su objetivo no es otro que modificar la estructura de incentivos de las grandes empresas farmacéuticas transnacionales, para que estas inviertan más en la investigación y producción de medicamentos y vacunas para curar o evitar enfermedades con enorme prevalencia en los PSVD. El desarrollo de estos fármacos y vacunas implica una enorme inversión y, dada la pobreza de los países afectados por estos males, no hay certeza de contar con un mercado en el cual venderlos. Ante esta situación, en febrero del 2007 algunos países (Canadá, Italia, Noruega, el Reino Unido y Rusia) y la Bill and Melinda Gates Foundation donaron 1.500 millones de dólares destinados a fomentar la investigación para encontrar una vacuna contra la enfermedad del neumococo (que ocasiona 11 millones de muertes infantiles por neumonía en los PSVD). Aunque esta medida ha sido criticada por no centrarse en la búsqueda de una vacuna contra la malaria o contra el VIH-SIDA, tal vez permita demostrar empíricamente la eficacia de este tipo de sistema, de cara a su implementación futura.

${ }^{12}$ Advanced Market Commitments.

${ }^{13}$ Global Alliance for Vaccines and Immunization. 


\section{$\mathrm{V}$}

\section{El endeudamiento externo}

El endeudamiento en el exterior ha servido tradicionalmente para complementar y reforzar los recursos internos de los PSVD. No obstante, como todo endeudamiento supone pago de intereses, estos países han debido enfrentar servicios de la deuda crecientes, que han ido lastrando sus posibilidades de crecimiento y exigiendo repetidas reestructuraciones o renegociaciones de su endeudamiento (crisis de deuda).

Dado que el servicio de la deuda absorbe una gran proporción de la ayuda oficial y de las corrientes de capital privado que reciben los PSVD, el Consenso de Monterrey estableció que la reducción o eliminación de este costo constituye una importantísima fuente adicional de financiación para el desarrollo. Naturalmente, la reducción del endeudamiento ha de venir acompañada de políticas que movilicen los recursos internos de los países receptores y que canalicen los recursos liberados del yugo de la deuda hacia la consecución de objetivos de desarrollo de largo plazo. Por otra parte, la condonación parcial o total de la deuda sólo será eficaz si, desde ese momento, el endeudamiento en que incurran dichos países se mantiene en niveles sostenibles y es asumible dadas sus condiciones económicas.

Si analizamos históricamente la evolución del endeudamiento de los PSVD, encontramos una situación especialmente dramática: si bien la mayoría de los países redujeron el peso de su deuda a partir de la década de 1990, los países más pobres y muy endeudados vieron cómo esta carga crecía. Como consecuencia, en 1996 se puso en marcha la iniciativa Países Pobres Muy Endeudados (PPME), con miras a reducir el nivel de endeudamiento de estos países, renegociar sus deudas con el Club de París y destinar los recursos liberados a objetivos de desarrollo.

Si bien la iniciativa PPME cubría inicialmente un periodo de tres años, en 1999 se convino una extensión —la iniciativa PPME reforzada- que concluyó en el 2006 (tras una prórroga desde el año 2004) y que benefició a 29 países. No obstante, el Banco Mundial y el FMI han establecido una lista de otros 11 países que en el 2006 reunían los requisitos para ser objeto de un proceso de condonación y reestructuración de la deuda similar al de la iniciativa PPME.

En el periodo 1996-2006, los efectos en los 29 países han sido moderadamente positivos. El valor presente del endeudamiento para el conjunto se ha reducido en dos tercios (en el 2005, el servicio de la deuda de estos 29 países representaba el 2,5\% de su PIB). El servicio de la deuda como proporción de sus exportaciones ha bajado, en promedio, del 16\% en 1996 al 8\% en el 2005. Además, parte del ahorro logrado sí ha ido a gasto en desarrollo; por ejemplo, el gasto público en programas de reducción de la pobreza en el conjunto de los 29 países creció del 6\% del PIB en 1999 a 9\% en el 2005.

No obstante, a pesar del éxito relativo de la iniciativa PPME, los elevados compromisos de gasto social de estos países han superado los recursos que liberó la iniciativa, llevándolos a seguir acrecentando su nivel de endeudamiento.

Dada la persistencia de los problemas de endeudamiento externo, han ido surgiendo nuevas iniciativas para paliarlos. Por ejemplo, una iniciativa del Reino Unido (Multilateral Debt Relief Initiative, MDRI) propone una reducción del $100 \%$ del servicio de la deuda y un canje de la deuda por créditos concedidos por las instituciones financieras internacionales. Canadá ha hecho una propuesta similar, pero con financiación bilateral. Los Estados Unidos también han hecho su aportación a través del FMI, el Fondo Africano de Desarrollo, la Asociación Internacional de Fomento y muchas otras entidades.

No obstante, todas estas iniciativas están dirigidas a países pobres muy endeudados, cuya deuda total está próxima a los 55.000 millones de dólares. Y se calcula que el endeudamiento total de los PSVD ronda los 2.300 miles de millones de dólares.

Los países muy endeudados pero no muy empobrecidos y los países endeudados que tienen ingresos medios quedan fuera de estas iniciativas y solo tienen la esperanza de que se concrete de algún modo la llamada Doctrina Evian del Club de París, que propugna una mayor laxitud a sus miembros a la hora de encarar el problema del endeudamiento.

En este sentido, y aunque las iniciativas desarrolladas hasta el momento han liberado recursos para que se los destine a objetivos de desarrollo de largo plazo, conviene no olvidar que el Secretario General de las Naciones Unidas definió el endeudamiento sostenible como aquel que permitiría a un país alcanzar los objetivos del milenio en el 2015 sin incrementar sus niveles de endeudamiento (Naciones Unidas, 2005). Naturalmente, 
esto implicaría, para todos los PPME y para buena parte de los PSVD de ingresos bajos y medios, sencillamente la condonación del monto total de su deuda.

En cualquier caso, y aunque se alcanzase una condonación de la deuda con el conjunto de los PSVD (lo que es inviable hasta ahora), la sostenibilidad del nuevo endeudamiento tendría mucho que ver con las posibilidades de crecimiento y de entrada en los circuitos

\section{VI}

\section{Conclusiones}

La internacionalización y la liberalización financieras se hallan entre los componentes más destacados del proceso de mundialización económica y sintetizan a la perfección el dualismo que caracteriza a ese proceso: oportunidad y amenaza.

Por un lado, y en teoría, pone a disposición del conjunto de las economías del planeta una cantidad gigantesca de recursos dispuestos a desplazarse al instante hacia las oportunidades de inversión más rentables. Por otro, el camino parece estar sembrado de escollos, tales como agentes oligopólicos y guiados por instintos grupales que dominan los mercados, recursos concentrados en muy pocos centros financieros, blanqueo de capitales, especulación, financiación de actividades ilegales y crisis financieras y cambiarias recurrentes.

Ante el tema del desarrollo, las finanzas internacionales presentan también esta condición dicotómica. Por una parte, sin su desarrollo de las últimas décadas sería difícil explicar los progresos de economías como China, India o las del sudeste asiático, que han dispuesto de corrientes continuadas de capital internacional para financiar su avance económico. El resto de los PSVD necesitan de las corrientes de capital privado y público para tratar de salir de la trampa de subdesarrollo y pobreza en que se encuentran.

Por otra parte, hay desamparos y amenazas que se ciernen sobre la conexión finanzas internacionales/ desarrollo. Los primeros porque muchos de los países que más recursos necesitan no están entre las naciones de destino de las corrientes de capital privado. Las segundas porque los países que sí reciben estas corrientes ven minados sus efectos benéficos por problemas de volatilidad, escasez y concentración geográfica, por el carácter especulativo de gran parte de ellas y, muy especialmente, por su reversibilidad. de comercio internacional de estos países. El endeudamiento sostenible debería ser parte de una estrategia de desarrollo más amplia que tratase los temas de comercio, finanzas y endeudamiento en forma conjunta y coherente. Ligando este asunto con la idea de reformar la arquitectura financiera internacional, parecería perentorio el establecimiento de una corte internacional de quiebras y suspensiones de pago.
En este contexto, la AOD está llamada a desempeñar el papel que se asigna habitualmente a toda intervención de naturaleza pública, institucional o, al menos, no estrictamente privada: el de compensar los desequilibrios y rellenar las lagunas que la iniciativa privada genera. No obstante, pese a la evolución relativamente satisfactoria de esta asistencia en los últimos años, quedan problemas importantes por solucionar: entre otros, los vinculados a su escaso monto total, su estructura y composición, su volatilidad y su alto grado de concentración espacial y de condicionalidad.

De todas estas dificultades, la más cercana al tema que se estudia aquí es que dicha AOD no basta para alcanzar los objetivos de desarrollo más imperativos. En efecto, como se señaló más atrás, la literatura sobre economía del desarrollo estima que se necesitan unos 50.000 millones de dólares adicionales por año de ayuda para alcanzar los objetivos del Milenio en la fecha prevista (Naciones Unidas, 2001; Atkinson, 2005). Por lo tanto, tres son las alternativas: i) aumentar la AOD tradicional, ii) idear e implementar medidas para lograr financiación adicional o iii) abandonar los objetivos del Milenio.

Descartando la tercera opción, parece claro que una combinación de las dos primeras es la alternativa con más posibilidades de éxito. Sin embargo, tanto la tendencia a la reducción del monto total de la AOD en los años 2006 y 2007 (debida principalmente a problemas estructurales relacionados con la composición de la AOD) como el poco avance en la aplicación de los instrumentos innovadores de financiación que se han analizado aquí, parecen obligarnos a asociar los objetivos de desarrollo del Milenio con esa secuencia final de las viejas películas de la década de 1940, en las que el protagonista camina y se pierde en la niebla. 
Para combatir esa imagen es preciso recoger algunas de las recomendaciones que han sido aportadas al debate con el propósito de colocar, por fin, a las finanzas internacionales al servicio del desarrollo. Se hará centrándose exclusivamente en los tres elementos fundamentales analizados en este ensayo: las corrientes de capital privado, la AOD y los instrumentos innovadores de financiación.

En primer lugar, habrá que reformar profundamente la arquitectura financiera internacional por la que discurren las corrientes financieras privadas internacionales. Esto es, los procesos de liberalización financiera deberían ser considerados, si acaso, el último paso de un largo camino, que debiera iniciarse con, entre otras medidas, la implementación de un marco institucional y legal adecuado, la creación de mercados financieros nacionales eficientes y profundos, transparentes, con buena difusión de la información y una sólida reglamentación financiera.

En cualquier caso, y si se opta por llevarlo a cabo, el proceso debería venir acompañado por la política económica en su conjunto; habría de ser secuencial, selectivo, paulatino, específico para cada economía y con posibilidad de desaceleración o reversión, y estar sujeto a la conducción y supervisión de las autoridades económicas nacionales e internacionales que, en todo momento, tendrían que disponer de los instrumentos de control y regulación pertinentes (García-Arias, 2002a).

Es preciso no solo mejorar la cantidad, la calidad y la transparencia de la información, sino adoptar una posición más activa en el proceso, supervisando y regulando los mercados financieros y cambiarios y las corrientes financieras que en ellos se canalizan. También, promover el establecimiento de un prestamista internacional de última instancia y de una corte internacional de quiebras y suspensiones de pago; tomar medidas para combatir el blanqueo de capitales; llevar a cabo acciones tendientes a dificultar el empleo de paraísos fiscales para evadir o eludir obligaciones tributarias y democratizar las instituciones financieras internacionales. ${ }^{14}$

En segundo lugar, es necesario respetar los compromisos cuantitativos de la AOD, destinando a ella un $0,7 \%$ del PIB mundial; velar por la calidad de los recursos aportados y, sobre todo, asegurar su estabilidad y constancia. La AOD debe financiar exclusivamente la lucha contra las desigualdades, el acceso de todos a los

\footnotetext{
${ }^{14}$ Véase más detalles en García-Arias (2002b).
}

derechos económicos y sociales fundamentales y la dotación de bienes públicos globales. ${ }^{15}$

En tercer lugar, parece imprescindible reformar los instrumentos de la AOD y reequilibrar su gestión para privilegiar la asociación más que la ayuda, entendiendo el desarrollo como un proceso de progreso económico y social, de reducción de las desigualdades y de acceso de todas las personas a los derechos humanos fundamentales. Hay que apoyar además las estrategias nacionales de desarrollo definidas soberanamente, dar prioridad a los servicios esenciales, reconocer el papel determinante que desempeñan las organizaciones de la sociedad civil, instaurar una verdadera asociación entre países donantes y receptores y apoyar la asociación de las sociedades civiles y el fortalecimiento de los procesos democráticos.

Por último, es perentorio poner en marcha algunos de los mecanismos innovadores de financiación para el desarrollo, específicamente el propuesto servicio de financiación internacional (IFF) y los impuestos supranacionales. Con respecto al IFF, habría que tener en cuenta que los fondos que recaudaría serían estrictamente adicionales a los procedentes de otras corrientes de AOD; se dirigirían a las poblaciones más pobres; apuntarían al ejercicio de los derechos humanos y al acceso a los bienes públicos globales; procurarían limitar de manera general las condicionalidades y eliminar las que no contribuyeran directamente a lograr los objetivos de desarrollo, y promoverían una gobernanza renovada, con mecanismos de toma de decisiones democráticos, representativos y transparentes y que asociaran a los países del sur y a sus representantes.

En lo referente a la fiscalidad, particularmente a la política impositiva, conviene no olvidar que la tributación supranacional viene a completar de manera indispensable a la nacional -en un contexto en el cual el papel de los sectores públicos ha sido afectado por el proceso de mundialización - por al menos tres razones (García-Arias, 2004): i) la necesidad de proveer los bienes públicos mundiales, los que requieren un financiamiento público internacional estable y sustentable; ii) la erosión del poder económico público y especialmente de su capacidad de conseguir los recursos necesarios para atender las necesidades colectivas de sus ciudadanos, y iii) la asimetría con la que son tratados en la fiscalidad tradicional los propietarios del factor capital, lo que ha socavado las bases impositivas tradicionales de los sectores públicos.

\footnotetext{
15 Para un análisis en profundidad de los Bienes Públicos Globales, consúltese Kaul y otros (1999, 2003) y García-Arias (2002b).
} 
Agosin, M. y R. Mayer (2000): Foreign Investment in Developing Countries: Does It Crowd in Domestic Investment, UNCTAD Discussion Paper, No 146, UNCTAD/OSG/DP/146, Ginebra.

Agüera Sirgo, J.M. y J. García-Arias (2000): Distorsiones del sistema financiero internacional: un impuesto sobre las transacciones financieras en divisas como alternativa, Revista de economía mundial, $\mathrm{N}^{\mathrm{o}}$ 2, Madrid, Universidad Complutense de Madrid.

Atkinson, A. (comp.) (2005): New Sources of Development Finance, Nueva York, Oxford University Press.

Banco Asiático de Desarrollo (2004): Asian Development Outlook, 2004, Manila.

Banco Mundial (1998): Assessing Aid: What Works, What Doesn't and Why, Nueva York, Oxford University Press. D.C.

Basu, A. y K. Srinivasan (2002): Foreign Direct Investment in Africa? Same Case Studies, IMF Working Paper, $\mathrm{N}^{\circ}$ 02/61, Washington, D.C., Fondo Monetario Internacional.

Beynon, J. (2003): Poverty Efficient Aid Allocations: Collier/Dollar Revisited, Overseas Development Institute Working Paper, $\mathrm{N}^{\circ} 2$, Londres, Economics and Statistics Analysis Unit, Overseas Development Institute.

BPI (Banco de Pagos Internacionales) (2007): Triennial Central Bank Survey of Foreign Exchange and Derivatives Market Activity in April 2007. Preliminary Global Results, Basilea. Disponible en: http://www.bis.org/publ/rpfx07.htm.

Bulir, A. y J. Hamann (2003): Aid Volatility: An Empirical Assessment, IMF Staff Papers, vol. 50, No 1, Washington, D.C., Fondo Monetario Internacional.

Burnside, C. y D. Dollar (2000): Aid, Policies and Growth, Policy Research Working Paper, No 1777, Washington, D.C., Banco Mundial.

Caballero, R. (2003): On the International Financial Architecture: Insuring Emerging Markets, NBER Working Paper, No 9570, Cambridge, Massachusetts, National Bureau of Economic Research.

CEPAL (Comisión Económica para América Latina y el Caribe) (2005): La inversión extranjera en América Latina y el Caribe, 2004, LC/G.2269-P, Santiago de Chile.

Collier, P. y J. Dehn (2001): Aid, Shocks and Growth, Policy Research Working Paper, $\mathrm{N}^{\circ}$ 2688, Washington, D.C., Banco Mundial.

Collier, P. y D. Dollar (2001): Can the world cut poverty in half? How policy reform and effective aid can meet the international development goals?, World Development, vol. 29, No 11 , Amsterdam, Elsevier.

Collier, P. y A. Hoeffler (2002): Aid, Policy and Growth in Postconflict Countries, Policy Research Working Paper, No 2902, Washington, D.C., Banco Mundial.

Comisión de las Comunidades Europeas (2005): New Sources of Financing for Development: A Review of Options, Commission Staff Working Paper, SEC (2005) 467, Bruselas.

Dalgaard, C-J. y H. Hansen (2001): On aid, growth and good policies, Journal of Development Studies, vol. 37, № 6, Londres, Taylor \& Francis.

Eatwell, J. (2002): The New International Financial Architecture: Promise or Threat, Cambridge, Cambridge Endowment for Research in Finance.

Eichengreen, B. (1999): Toward a New International Financial Architecture: A Practical Post-Asia Agenda, Washington, D.C., The Institute for International Economics.

Eichengreen, B., R. Hausmann y U. Panizza (2003): Currency Mismatches, Debt Intolerance, and Original Sin: Why They Are Not the Same and Why It Matters, NBER Discussion Paper, $\mathrm{N}^{\mathrm{o}}$ 10036, Cambridge, Massachusetts, National Bureau of Economic Research.
García-Arias, J. (2002a): La crisis cambiaria y financiera de la ASEAN-4: liberalización financiera disfuncional y comportamiento de rebaño, Problemas del desarrollo. Revista latinoamericana de economía, vol. 33, No 129, México, D.F., Universidad Nacional Autónoma de México.

(2002b): Economía política de la estabilidad cambiaria. Una perspectiva desde la teoría de los bienes públicos globales, Madrid, CES.

(2004): Mundialización y sector público: mitos y enseñanzas de la globalización financiera, Comercio exterior, vol. 54, $\mathrm{N}^{\circ} 10$, México, D.F., Banco Nacional de Comercio Exterior.

(2006): Information cascades and currency crises: a theoretical analysis, Investigación económica, $\mathrm{N}^{\mathrm{o}} 255$, México, D.F., Universidad Nacional Autónoma de México.

Griffith-Jones, S., R. Gottschalk y J. Cailloux (comps.) (2003): International Capital Flows in Calm and Turbulent Times: The Need for New International Architecture, Ann Arbor, University of Michigan Press.

Hansen, H. y F. Tarp (2000): Aid effectiveness disputed, Journal of International Development, vol. 12, $\mathrm{N}^{\circ} 3$, Nueva York, Wiley.

Hanson, G. (2001): Should Countries Promote Foreign Direct Investment?, CID Discussion Paper Series, $N^{\circ}$ 9, Nueva York, Naciones Unidas.

HM Treasury/Departamento de Desarrollo Internacional (2003): International Finance Facility, Londres.

Kaul, I., I. Grunberg y M. Stern (1999): Global Public Goods: International Cooperation in the $21^{\text {st }}$ Century, Nueva York, Oxford University Press.

Kaul, I. y otros (2003): Providing Global Public Goods. Managing Globalization, Nueva York, Oxford University Press.

Kenen, P. (2001): The International Financial Architecture: What's New? What's Missing, Washington, D.C., Institute for International Economics.

Morrissey, O. (2001): Does aid increase growth?, Progress in Development Studies, vol. 1, No 1, Sage Publications.

Naciones Unidas (2001): Informe del Grupo de Alto Nivel sobre la Financiación para el Desarrollo, Nueva York.

(2002): Informe de la Conferencia Internacional sobre la Financiación para el Desarrollo (Monterrey, México, 18 a 22 de marzo), A/CONF. 198/11, Nueva York.

(2005): Un concepto más amplio de la libertad: desarrollo, seguridad y derechos humanos para todos, Nueva York.

Nissanke, M. (2005): Revenue potential of the Tobin Tax for development finance: a critical appraisal, en A. Atkinson (comp.), New Sources of Development Finance, Nueva York, Oxford University Press.

Ocampo, J.A. (1999a): La reforma financiera internacional: una agenda ampliada, Revista de la CEPAL, N 69, LC/G.2067-P, Santiago de Chile, diciembre.

(1999b): Hacia una nueva arquitectura financiera internacional. Informe del Grupo de Trabajo del Comité Ejecutivo de Asuntos Económicos y Sociales de las Naciones Unidas, LC/G. 2054, Santiago de Chile, marzo.

Ocampo, J.A., J. Kregel y S. Griffith-Jones (2007): International Finance and Development, Londres, Zed Books.

oCDE (Organización de Cooperación y Desarrollo Económicos) (2008), Net Official Development Assistance in 2007. Preliminary data for 2007. Disponible en: http:www.oecd.org/dac.

Olivié, I. y F. Steinberg (2007): Un balance de la ayuda al desarrollo 2006 : ¿Disminuye la ayuda?, ARI, $\mathrm{N}^{\circ} 56$, Madrid, Real Instituto Elcano.

Palazuelos, E. (1998): La globalización financiera. La internacionalización del capital financiero a finales del siglo XX, Madrid, Síntesis.

Pallage, S. y M.A. Robe (2001): Foreign aid and the business cycle, Review of International Economics, vol. 9, $\mathrm{N}^{\circ}$ 4, Oxford, Blackwell Publishing. 
Sandmo, A. (2005): Environmental taxation and revenue for development, en A. Atkinson (comp.), New Sources of Development Finance, Nueva York, Oxford University Press.

UNCTAD (Conferencia de las Naciones Unidas sobre Comercio y Desarrollo) (2003): World Investment Report, 2003. FDI Policies for Development: National and International Perspectives, Ginebra.

Weller, Ch. (2001): The Supply of Credit by Multinational Banks in Developing and Transition Economies: Determinants and Effects, DESA Discussion Paper, No 16, ST/ESA/2001/DP.16, Nueva York, Naciones Unidas. 